\title{
Menstrual Characteristics of Pubertal Girls: A Questionnaire-Based Study in Turkey
}

\author{
Ihsan Esen1, Baran Oğuz2, Hepsen Mine Serin2 \\ ${ }^{1}$ Fırat University Faculty of Medicine, Department of Pediatrics, Division of Pediatric Endocrinology, Elazığ, Turkey \\ ${ }^{2}$ Firat University Faculty of Medicine, Department of Pediatrics, Elazığ, Turkey
}

\section{WHAT IS ALREADY KNOWN ON THIS TOPIC?}

Menstrual-associated complaints are observed commonly in adolescents. In particular, pain accompanying the menstrual period is the most frequently reported complaint.

\section{WHAT THIS STUDY ADDS?}

This study determined the menstrual characteristics of pubertal adolescent Turkish girls and the association between menstrual cycle features and interference with life activities.

\section{ABSTRACT}

Objective: Clinicians should show an awareness on the menstrual characteristics of adolescent girls which may differ from adults in some aspects. To define menstrual cycle features among high school girls residing in a city center in southeastern Turkey.

Methods: A cross-sectional survey was conducted on 1256 girls attending a high school located in the city center of Elazığ, Turkey. Data from 879 girls (median age, 16.2 years; range, 13.6-19.2 years) who agreed to participate in the study and had started to menstruate were evaluated.

Results: Mean age at menarche was $12.7 \pm 1.3$ years (range, 8.2-17.3 years). The mean cycle duration was $28.7 \pm 4.4$ days, and the mean menstrual flow lasted $5.9 \pm 1.3$ days. Severe, moderate, and mild dysmenorrhea was reported in $29 \%, 43 \%$, and $28 \%$ of the girls, respectively, and $52 \%$ used analgesics for dysmenorrhea. A total of $34 \%$ of the girls defined their menstrual cycle as irregular, and $32 \%$ reported school absenteeism due to menstruation-associated complaints (pain and/or heavy bleeding). Menstrual bleeding affected attendance to classes and other school activities, daily work, social, family, and friend relationships, as well as sports/exercise activities in $43 \%, 49 \%, 58 \%, 48 \%, 44 \%$, and $60 \%$ of the participants, respectively. In total, $30 \%$ of the responders had a problem with menstruation, and $12 \%$ and $17 \%$ of these stated that they consulted a primary care physician or specialist, respectively.

Conclusion: Dysmenorrhea was found to be common in adolescent Turkish girls and to affect daily life in approximately half of the girls.

Keywords: Adolescent, menstrual characteristics, dysmenorrhea

Conflict of interest: None declared

Received: 30.03 .2015

Accepted: 30.11 .2015

\section{Introduction}

Puberty is the period of human development during which secondary sexual characteristics appear, sexual maturation occurs, and reproductive capacity is attained. Ovulation and menstruation begin in girls during this period (1). Although this period usually

Address for Correspondence

Ihsan Esen MD, Firat University Faculty of Medicine, Department of Pediatrics, Division of Pediatric Endocrinology, Elazığ, Turkey

Phone: +90 5055252333 E-mail: esen_ihsan@yahoo.com

OJournal of Clinical Research in Pediatric Endocrinology, Published by Galenos Publishing. 
passes without important problems, menstruation-associated complaints are observed commonly in adolescents. In particular, pain accompanying the menstrual period is the most frequently reported complaint $(2,3,4,5,6,7,8)$. Irregular menstrual cycles are also reported frequently during the first years after menarche, possibly due to immaturation of the hypothalamic-pituitary-gonadal axis in the young adolescent $(2,4)$. Physical, psychological, and emotional symptoms are also observed before and during menstruation in almost all adolescents $(4,9,10,11)$. Mainly pain and also other symptoms occurring during menstruation affect daily life activities, can decrease school performance, and also increase the rate of school absenteeism $(2,3,4,6,7,8,12)$.

In this study, we attempted to define the typical menstrual characteristics of adolescent girls residing in Elazığ city, Turkey and to investigate the effects of menstruation-associated complaints on life activities.

\section{Methods}

\section{Subjects and Setting}

The study was conducted in 2014 and consisted of a crosssectional survey on girls attending six high schools randomly selected from different locations in the city center of Elazığ, Turkey. Questionnaires were distributed to 1256 girl students in grades 9-12 to be completed at home and 911 (72.5\%) returned the completed questionnaire. Thirty-two students whose menstrual periods had not yet started were excluded from the analysis. Data from 879 pubescent girls who agreed to participate in the study and who had started to menstruate (median age, 16.2 years; range, 13.6-19.2 years) were evaluated.

The answers were transferred to an electronic database.

\section{Questionnaire Form}

The questionnaire form was prepared in Turkish and was based on a form used previously by Parker et al (4). The questionnaire was tried and assessed in 10 high school girls prior to the study. Based on the feedback, some complex statements were revised, and other questions were excluded. The final questionnaire comprised 82 questions divided into six sections. Students were asked to select from the options yes/ no or true/false or to use a 1-10 scale for their answers. The questionnaire took about 20 min or less to complete. Menstrual pattern, duration and intensity of menstruation, school absenteeism due to menstruation, pain during the menstrual cycle, use of painkillers, physical-emotional symptoms during the menstrual cycle, and the effects of menstruation on various life activities were evaluated by the questionnaire. The menstrual period was considered regular if it occurred at intervals of 20-45 days. Pain during menstruation was categorized as severe (8-10 on a 0-10-point scale), moderate (4-7), or mild or no pain (0-3).

\section{Ethical Evaluation and Statistical Analysis}

The study protocol was approved by the Non-Interventional Studies Ethics Committee of Firat University. Written informed consent was obtained from parents and the participating children.

The data were evaluated using the Statistical Package for the Social Sciences 18.0 program (SPSS Inc., Chicago, IL, USA). Incidence data are presented as percentages, and numerical data are expressed as means \pm standard deviation. The chi-square test was used to compare categorical data, and the t-test was used to compare the numeric data. Statistical significance was accepted at $\mathrm{p}<0.05$.

\section{Results}

The subjects had started their menstrual cycles $3.5 \pm 1.6$ years previously. Mean age at menarche was $12.7 \pm 1.3$ years (range, 8.2-17.3 years); 22 girls (2.5\%) had experienced their first period before age 10 years, and 14 (1.6\%) after age 15 years. The mean menstrual period duration was $28.7 \pm 4.4$ days, and the mean length of menstruation was $5.9 \pm 1.3$ days (range, 3-10 days) in 581 (66.1\%) girls who defined their periods as regular. Approximately 62\% (508/818) of the girls stated that their menstrual flow contained clots, whereas 5.2\% (43/824) and $8.0 \%(66 / 824)$ stated that they experienced spotting before and in the middle of their menstrual period, respectively. Approximately 24\% (213/879) of the girls defined their periods as irregular. Age at menarche and chronological age were comparable in girls with regular periods compared with those with irregular periods ( $p>0.05$ ). Girls with irregular periods had a shorter duration of menstrual flow than did those with regular periods ( $3.2 \pm 1.6$ vs. $3.5 \pm 1.5$ days, respectively) $(p<0.05)$. The girls who had reached menarche $>2$ years before the present study had significantly fewer irregular periods (48/506; 9.6\%) compared to girls who had reached menarche $\leq 2$ years before the study $(165 / 373 ; 44.6 \%)(p<0.001)$.

The 10 most frequently reported symptoms are listed in Table 1.

\section{Pain During Menstruation (Dysmenorrhea)}

Approximately $92 \%$ of the responders had dysmenorrhea, and the pain was reported as severe, moderate, and mild or no pain in $28.8 \%$ (245/850), $43.3 \%$ (368/850), and $27.9 \%$ (237/850) of the subjects, respectively. Approximately $52 \%$ (412/793) of the girls reported that they used analgesics on their own during their menstrual cycle. Paracetamol was the commonest analgesic used (76\%; 290/382), whereas 20\% (77/382) and 3\% (11/382) reported that they took oral and parenteral nonsteroidal anti-inflammatory drugs (NSAIDs). The data showed that $70 \%$ (319/457) of the girls who reported using an analgesic obtained a moderate to good (range, 4-10 on a 10-point scale) analgesic response from the drug. Only $1 \%(4 / 382)$ of the subjects had consulted a healthcare facility 
because of menstruation-related pain. Sixty-three $(7.5 \%)$ girls reported that they never experienced pain during their period.

\section{Menstrual Cycle-Related Problems}

Approximately $12.0 \%$ (97/811), 16.7\% (137/809), and 4.3\% (38/807) of the subjects reported that they had consulted a primary-care physician, a specialist, or herbal drug dealer, respectively, for menstrual cycle-related problems. Analgesic tablets were recommended to 59 subjects for use during their menstrual cycle. Five subjects were prescribed oral contraceptive tablets because of a diagnosis of polycystic ovary syndrome.

\section{Effects of Menstruation on Life Activities}

Approximately 32\% (261/822) of subjects were absent from school due to menstrual cycle-related reasons. Menstruation caused a 1 day absence for most girls (78.1\%), but 2- (17.4\%) and 3 -day absences (4.5\%) in $17.4 \%$ and $4.5 \%$ of the subjects, respectively. The causes for school absenteeism were pain in $88.2 \%$, heavy bleeding in $4.9 \%$, and nausea in $2.3 \%$ of the subjects. The effects of menstruation on seven groups of life activities in this group of subjects are shown in Table 2. Complaints related to menstruation and their effects on life activities are given in Table 3 .

\section{Self-Perceptions of the Menstruation Cycle}

The perceptions of menstruating girls were evaluated in the true/false part of the questionnaire, which consisted of 30 statements. The 10 items most commonly considered to apply to the participant are shown in Table 4.

\section{Discussion}

Our results show that the menstrual characteristics of adolescent girls living in Elazığ, Turkey are similar to the

Table 1. The 10 most common menstruation-related symptoms reported in the study group

\begin{tabular}{|l|l|l|l|}
\hline Symptoms & $\begin{array}{l}\text { Reported in } \\
\text { number of girls }\end{array}$ & $\begin{array}{l}\text { Total number } \\
\text { of responders }\end{array}$ & $\%$ (95\% CI) \\
\hline Lower back pain & 635 & 817 & 78 (75-81) \\
\hline Fatigue & 637 & 822 & 77 (75-80) \\
\hline Malaise & 621 & 814 & $76(73-79)$ \\
\hline Pelvic pain-moderate & 372 & 560 & 66 (63-70) \\
\hline Pelvic pain-stabbing & 349 & 541 & $65(60-69)$ \\
\hline $\begin{array}{l}\text { Abdominal bloating } \\
\text { (flatulence) }\end{array}$ & 511 & 829 & $62(58-65)$ \\
\hline Altered appetite & 476 & 793 & 60 (57-63) \\
\hline Headache & 438 & 807 & $54(51-58)$ \\
\hline $\begin{array}{l}\text { Frequent urge to } \\
\text { urinate }\end{array}$ & 370 & 811 & $46(42-49)$ \\
\hline Cl: confidence interval & & & \\
\hline
\end{tabular}

typical characteristics reported in other studies (13). The duration of the menstrual cycle varies in adolescent girls, and their periods typically become regular as they age (14). Approximately half of the girls we surveyed who reached menarche $<2$ years previously reported irregular periods, whereas this number was very low in girls who had started menstruating $>2$ years ago. The extremes in menstrual cycle length are wider among adolescents as compared to adult women. However, a menstrual cycle beyond the 20-45-day range in young girls is not an expected finding and requires evaluation (13). No subject in our study reported periods more frequent than every 20 days, and a limited number of girls reported that they menstruated less frequently than every 45 days.

Previous studies show that pain usually accompanies menstruation in adolescents, with a reported pain incidence of $39-93 \%(2,3,4,5,6,7,8,15,16)$. In our study, the incidence of pain was at the upper limit and is the highest rate reported in Turkey. The frequency of analgesic use during menstruation was similar to rates reported previously $(41-80 \%)(4,5,6)$. Girls in our cohort used paracetamol most often, which is consistent

\begin{tabular}{|c|c|c|c|}
\hline & $\begin{array}{l}\text { Number of } \\
\text { responders }\end{array}$ & $\begin{array}{l}\text { Serious } \\
\text { interaction* } \\
\mathrm{n}(\%)\end{array}$ & $\begin{array}{l}\text { Low } \\
\text { interaction** } \\
\mathrm{n}(\%)\end{array}$ \\
\hline Sport and exercise & 591 & $353(59.7)$ & $238(40.3)$ \\
\hline Social activities & 551 & $318(57.8)$ & $233(42.2)$ \\
\hline Family relationships & 476 & $293(49.0)$ & $305(51.0)$ \\
\hline Daily activities & 598 & $230(48.3)$ & $246(51.7)$ \\
\hline Friendships & 482 & $214(44.3)$ & $268(55.7)$ \\
\hline School activities & 520 & $224(43.0)$ & $296(57.0)$ \\
\hline School attendance & 371 & $103(27.8)$ & $268(72.2)$ \\
\hline $\begin{array}{l}{ }^{*} \text { Serious interaction: } 5-10 \\
{ }^{*} \text { Low interaction: } 0-4 \text { rat }\end{array}$ & $\begin{array}{l}\text { ting on a 10-poir } \\
\text { on a } 10 \text {-point s }\end{array}$ & scale & \\
\hline
\end{tabular}

Table 3. Complaints related to menstruation with serious effects on life activities reported in the study group

\begin{tabular}{|l|l|l|l|}
\hline Complaint & $\begin{array}{l}\text { Number } \\
\text { of responders }\end{array}$ & $\begin{array}{l}\text { Serious } \\
\text { effect* }^{*} \\
\mathbf{n}(\%)\end{array}$ & $\begin{array}{l}\text { Low or no effect** } \\
\mathbf{n}(\%)\end{array}$ \\
\hline Feeling sick/bad & 681 & $509(74.3)$ & $172(25.3)$ \\
\hline Malaise & 677 & $501(74.0)$ & $176(26.0)$ \\
\hline Pain & 725 & $523(72.1)$ & $202(27.9)$ \\
\hline $\begin{array}{l}\text { Exhaustion, } \\
\text { fatigue }\end{array}$ & 684 & $486(71.1)$ & $198(28.9)$ \\
\hline Heavy bleeding & 621 & $370(59.6)$ & $251(40.4)$ \\
\hline $\begin{array}{l}\text { *Serious effect: 5-10 rating on a 10-point scale } \\
\text { **Low or no effect: 0-4 rating on a 10-point scale }\end{array}$ \\
\hline
\end{tabular}


with previous findings, but more recent studies reveal a trend toward use of NSAIDs $(4,6,17)$. A few subjects reported that they suffered from very severe pain during their periods that required a visit to a healthcare facility. These girls should be examined for possible pathologies, such as endometriosis. Parker et al (4) reported that $85 \%$ of subjects obtain a moderate-good analgesic response from the painkillers they use. We found a rate of $70 \%$. However, both Parker et al (4) and our studies lacked sufficient data to determine whether the unsatisfactory analgesic responses were caused by too low doses, frequent drug use, or underlying serious pathologies, such as endometriosis.

Approximately one-third of the adolescents in our study reported severe pain during their menstrual cycle, which was similar to rates observed previously $(4,6,7,9,15,18)$. The menstrual cycle-related school absenteeism rate of $32 \%$ observed here was also consistent with previous reports $(2,3,4,6,7,8,9,12,15,18)$. Pain was reported to be the most common complaint causing school absenteeism $(2,3,4,6,7,8)$. Similarly, our results showed that severe pain was the most common complaint causing school absenteeism during the menstrual cycle of Turkish adolescent girls. A few girls reported heavy menstrual bleeding as the cause of school absenteeism. We discovered that menstrual pain and symptoms substantially affected daily life activities of these adolescents. Similar results were reported previously in studies conducted in other countries $(4,6,7,8)$.

Puberty is regulated by the hypothalamus through complex genetic mechanisms and is affected by ethnicity, nutritional status, and many other environmental factors. Age at menarche has become younger in developed countries since the mid-20th century, which has been associated with improved nutritional and economic status (19). This trend has stopped, probably because of stabilized socioeconomic status (20). The first study that investigated mean age at menarche in Turkish girls was conducted by Neyzi et al (21) in Istanbul in 1973, who found the mean age at menarche to be 12.4 years. Atay et al (22) conducted a study in Istanbul in 2009 and reported a mean age of menarche of 12.7 years. Our results show a mean age at menarche of 12.7 years, which supports the notion that the trend towards a younger menarche has stopped in Turkey, as reported by Atay et al (22).

To conclude, it may be said that the majority of the adolescent girls evaluated perceived their periods to be normal. However, mild to moderate dysmenorrhea with an impact on school attendance and social life was reported as a common occurrence. More effective and judicious use of painkillers can go a long way in ameliorating these problems. Also increasing awareness and educating adolescent girls and their parents regarding normal periods and related problems would have favorable effects such as a reduction in school absenteeism. Pediatricians interacting with adolescent girls should always discuss the menstrual periods, helping the girls and their families differentiate physiologic from pathologic states.

\section{Ethics}

Ethics Committee Approval: This present study was approved by the Ethics Committee of Firat University in 2013, Informed Consent: It was taken.

Peer-review: External peer-reviewed.

\section{Authorship Contributions}

Concept: Ihsan Esen, Design: Ihsan Esen, Baran Oğuz, Hepsen Mine Serin, Data Collection or Processing: Ihsan Esen, Baran Oğuz, Hepsen Mine Serin, Analysis or Interpretation: Ihsan Esen, Baran Oğuz, Hepsen Mine Serin, Literature Search: Ihsan Esen, Writing: Ihsan Esen.

Financial Disclosure: The authors declared that this study received no financial support.

Table 4. The 10 questionnaire items most commonly considered to apply to the study group

\begin{tabular}{|l|l|l|l|}
\hline Symptoms & Frequency & Number of responders & \% (95\% CI) \\
\hline I usually have my period every month & 703 & 823 & $85(83-87)$ \\
\hline My periods make me anxious/uncomfortable & 547 & 790 & 69 (66-72) \\
\hline I think my periods are usually normal & 533 & 770 & $69(66-72)$ \\
\hline I talk to a family member about my periods & 515 & 802 & $64(61-67)$ \\
\hline I think my periods are normal & 513 & 800 & 64 (61-67) \\
\hline I get my period every month. I've never missed a month & 512 & 808 & $63(60-66)$ \\
\hline I become nervous/problematic before and during my period & 473 & 801 & $59(56-62)$ \\
\hline I want to disappear during my period & 411 & 794 & $52(49-55)$ \\
\hline $\begin{array}{l}\text { I feel suffocated/bored before and during my period and cannot } \\
\text { cope }\end{array}$ & 408 & 802 & $51(48-54)$ \\
\hline I talk to friends about my period & & 786 & 50 (47-53) \\
\hline Cl: confidence interval & 392 & & \\
\hline
\end{tabular}




\section{References}

1. Rosenfield RL, Cooke DW, Radovick S. Puberty and its disorders in the female. In: Sperling MA (ed). Pediatric Endocrinology. Philadelphia, Elsevier Saunders, 2014;569663.

2. Vicdan K, Kukner S, Dabakoglu T, Ergin T, Keles G, Gokmen O. Demographic and epidemiologic features of female adolescents in Turkey. J Adolesc Health 1996;18:54-58.

3. Eryilmaz G, Ozdemir F, Pasinlioglu T. Dysmenorrhea prevalence among adolescents in eastern Turkey: its effects on school performance and relationships with family and friends. J Pediatr Adolesc Gynecol 2010;23:267-272. Epub 2010 May 21

4. Parker MA, Sneddon AE, Arbon P. The menstrual disorder of teenagers (MDOT) study: determining typical menstrual patterns and menstrual disturbance in a large populationbased study of Australian teenagers. BJOG 2010;117:185192.

5. Demir SC, Kadayyfcy TO, Vardar MA, Atay Y. Dysfunctional uterine bleeding and other menstrual problems of secondary school students in Adana, Turkey. J Pediatr Adolesc Gynecol 2000;13:171-175.

6. Suvitie PA, Hallamaa MK, Matomaki JM, Makinen JI, Perheentupa $\mathrm{AH}$. Prevalence of pain symptoms suggestive of endometriosis among finnish adolescent girls (TEENMAPS study). J Pediatr Adolesc Gynecol 2016;29:97-103. Epub 2015 Jul 11

7. Pitangui AC, Gomes MR, Lima AS, Schwingel PA, Albuquerque AP, de Araujo RC. Menstruation disturbances: prevalence, characteristics, and effects on the activities of daily living among adolescent girls from Brazil. J Pediatr Adolesc Gynecol 2013;26:148-152. Epub 2013 Mar 16

8. Zannoni L, Giorgi M, Spagnolo E, Montanari G, Villa G, Seracchioli R. Dysmenorrhea, absenteeism from school, and symptoms suspicious for endometriosis in adolescents. J Pediatr Adolesc Gynecol 2014;27:258-265. Epub 2014 Apr 18

9. Wilson CA, Keye WR Jr. A survey of adolescent dysmenorrhea and premenstrual symptom frequency. A model program for prevention, detection, and treatment. J Adolesc Health Care 1989;10:317-322.
10. Vichnin M, Freeman EW, Lin H, Hillman J, Bui S. Premenstrual syndrome (PMS) in adolescents: severity and impairment. $J$ Pediatr Adolesc Gynecol 2006;19:397-402.

11. Allen LM, Lam AC. Premenstrual syndrome and dysmenorrhea in adolescents. Adolesc Med State Art Rev 2012;23:139-163.

12. Banikarim C, Chacko MR, Kelder SH. Prevalence and impact of dysmenorrhea on Hispanic female adolescents. Arch Pediatr Adolesc Med 2000;154:1226-1229.

13. Adams Hillard PJ. Menstruation in adolescents: what's normal, what's not. Ann N Y Acad Sci 2008;1135:29-35

14. No authors listed. World Health Organization multicenter study on menstrual and ovulatory patterns in adolescent girls. II. Longitudinal study of menstrual patterns in the early postmenarcheal period, duration of bleeding episodes and menstrual cycles. World Health Organization Task Force on Adolescent Reproductive Health. J Adolesc Health Care 1986;7:236-244.

15. Klein JR, Litt IF. Epidemiology of adolescent dysmenorrhea. Pediatrics 1981;68:661-664.

16. Sultan C, Paris F, Feki M, Rasandratana A, Attal G, Legasal P, Molinier A, Lumbroso S, Dumas R. Épidémiologie de la dysménorrhée de l'adolescente en France. Annales de pédiatrie 1999;46:518-525.

17. Hillen TI, Grbavac SL, Johnston PJ, Straton JA, Keogh JM. Primary dysmenorrhea in young Western Australian women: prevalence, impact, and knowledge of treatment. J Adolesc Health 1999;25:40-45.

18. Teperi J, Rimpela M. Menstrual pain, health and behaviour in girls. Soc Sci Med 1989;29:163-169.

19. Euling SY, Selevan SG, Pescovitz OH, Skakkebaek NE. Role of environmental factors in the timing of puberty. Pediatrics 2008;121(Suppl 3):167-171

20. Sorensen K, Mouritsen A, Aksglaede L, Hagen CP, Mogensen SS, Juul A. Recent secular trends in pubertal timing: implications for evaluation and diagnosis of precocious puberty. Horm Res Paediatr 2012;77:137-145. Epub 2012 Apr 12

21. Neyzi O, Alp H, Orhon A. Sexual maturation in Turkish girls. Ann Hum Biol 1975;2:49-59.

22. Atay Z, Turan S, Guran T, Furman A, Bereket A. Puberty and influencing factors in schoolgirls living in Istanbul: end of the secular trend? Pediatrics 2011;128:40-45. Epub 2011 Jun 13 